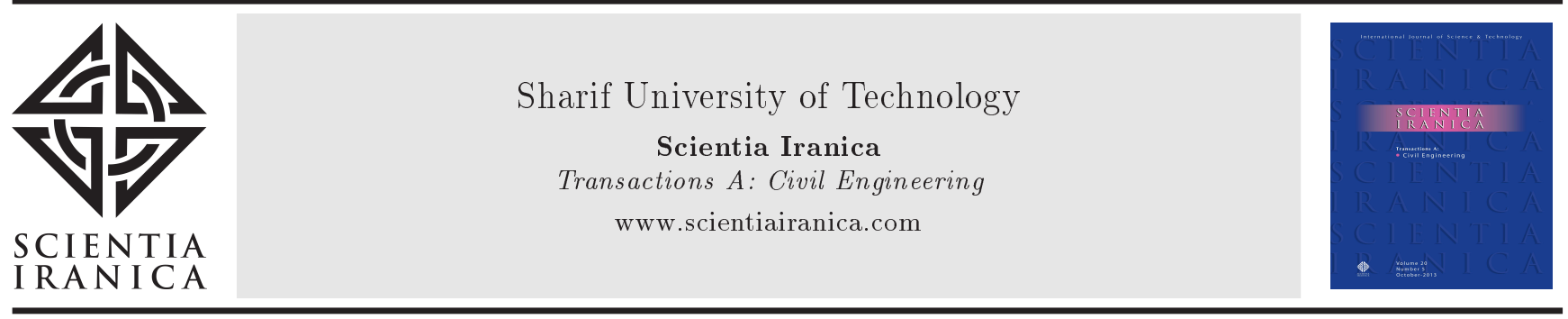

Brief Note

\title{
Sustainable health promotion and resilience in urban environment
}

\author{
P. Raeissi ${ }^{a}$ and M.T. Ahmadian ${ }^{b, *}$ \\ a. School of Management and Medical Information Science, Iran University of Medical Sciences, Tehran, Iran. \\ b. School of Mechanical Engineering, Bioengineering Research Center, Sharif University of Technology, Tehran, Iran. \\ Received 30 September 2015; accepted 11 January 2016
}

\section{KEYWORDS}

Sustainable health;

Resilience city.

\begin{abstract}
A part of resilience and sustainability in any urban environment is establishing and maintaining health. Sustainability in health is a dynamic process in which growth of physical, mental, and social health is guaranteed. A city is sustainable when all aspects of life, such as economy, environment, health, and infrastructure, are well defined and very often subjected to optimization.
\end{abstract}

(C) 2016 Sharif University of Technology. All rights reserved.

\section{Introduction}

Resiliency is the capacity for future impacts due to disasters, such as earthquakes, climate changes, health problems, and epidemics. In order to help the cities, careful planning must be made prior to any events or disasters.

Establishing and maintaining policies to improve health and quality of life for all is a part of sustainability in health. Other factors in sustainability are social justice and socioeconomics. The International Covenant on Economic, Social, and Cultural Rights states that "the enjoyment of the highest standards of health is one of the fundamental rights of every human being without distinction of race, religion, political belief, economy, and social condition". In every society, health is a key driving force for sustainable development. Health is a highly strategic and important issue for the resiliency in every country and state.

\footnotetext{
*. Corresponding author. Tel: +982166165503; Fax: +982166000021

E-mail addresses: raeissi.p@IUMS.ac.ir (P. Raeissi); ahmadian@sharif.edu (M.T. Ahmadian)
}

\section{Dynamic cities}

Our cities are being redefined daily based on social, political, and environmental factors [1]. Even though all processes and regulations are subjected to change dynamically in a sustainable city, the proper number of clinics, hospitals, doctors, and nurses should be defined per capita. While even distribution is necessary, the collaboration of the subsystems is also essential in any harsh event. At present, the number of beds in hospitals per 1,000 population in different countries varies: Japan 13, Germany 8, Korea 10, and Iran 1.7. However, it is not clear what the optimum number of hospital beds per 1,000 population is. For a sustainable city in which health promotion is a part of growth policy, the number of physicians per 1,000 population becomes important. This number based on WHO standard is about 2.5, while that of Iran is about 1 . Also, pretraining and awareness of the specialists and people play an important role in preventing the spread of epidemics throughout the societies.

Development of strategies for cities to confront the future shocks due to unexpected events is crucial. To maintain sustainability, dynamic policies in health 
promotion are very important. Regular vaccination, health education, and clean environment, such as clean water, clean air, and clean city, are the elements under which sustainable health can be achieved.

\section{Sustainable criteria for health}

Maintaining and growth of physical, mental, and social health within the society as an important factor in sustainability, economic growth, and happiness along with dynamic social rules and regulations must be in place. This includes the following: Proper number of hospitals, physicians, and nurses mass media such as TV, theater, cinema, magazine, and newspapers; City Hall such as park development, exercise facilities, clean environment, and traffic human relationship such as Non-Governmental Organizations (NGO), playgrounds, libraries, etc.

\section{Poverty prevention}

Poverty reduction strategies ought to be the goal of City Hall and economic strategy. Poverty is one of the roots of ill-health; ill-health causes poverty as well.

Poor health has adverse effects on sustainability and development of cities. Environmental degradation, uneven development, and inequities also cause poor human health and suffering. Life expectancy of 75.2 years in developed countries, 61.4 years in all developing countries, and 49.2 years in the least developed countries indicate the health development in these countries. Poor environment condition and spread of the epidemics result in the life expectancy of less than 45 years for 200 million people in countries of Africa and Asia. One of the reasons for the lower life expectancy in many of these countries is the spread of HIV/AIDS, addiction, and poverty.

One of the tools helping the sustainability of the cities is virtual communication via Internet and social media. The Internet is making cities more essential than ever through a networked urban infrastructure. People's access to communication and information in health promotion field could be available through the networking of the cities. Global information and communications facilitate resiliency, specifically in the health improvement. Information exchange and mobility throughout the cities, as one of the key points, should be addressed in any resilient city in the face of adversity. Internet is an essential part of collaboration among people in every urban life and can highly affect health promotion and sustainability.

Human capability and well-being solely depend on health; total satisfaction of other aspects of life also depends on well-being and capability.

Ecosystem and human health are the integral part of a sustainable and prosperous human life.
A healthy ecosystem also guarantees the human health as well. Part of the epidemic and disease can be prevented by healthy ecosystems. Due to the infectious diseases resulting from environment, in these countries, one in five children fails to reach his or her fifth birthday. The child mortality rate based on WHO reports was 156 per 1,000 live births in the least developed countries in 2000, compared to 81 in all developing countries and 11 in developed countries.

It is also estimated that 35 million children in developing countries and 8 million in developed countries suffer from obesity and are overweight, although in relative terms, the percentages are higher in developed countries. Childhood obesity requires an interdisciplinary approach to address the current eating habits and physical activity of our youth [2].

In the developing countries, air pollution is gradually becoming a risk factor in health. Air pollution is a major contributor to the global burden of disease and mortality; it is estimated to cause 1.3 million deaths worldwide each year [3,4]. Public health is becoming more deeply integrated into city policymaking and programming; it is likely to gain even more importance in the coming years with such movements as health in all policies (WHO). Encouragement of the governments, communities, organizations, and NGOs to focus their issue on policies for the improvement, health, and wellbeing will promote health status for sustainable cities. Completing this task requires cooperation of all sectors of a society.

\section{Conclusion}

Increasing flow of information and available data enable the cities to operate much better through internet and social networks. It is necessary to integrate health with policies for a sustainable and resilient city. Planning for maximizing physical, mental, and social health within the society must be a part of this integration. Dynamic interventions for the optimization of people health to achieve the sustainable and resilient city must be the goal in each urban environment. Air pollution is one of the hazard element in health promotion. Municipal managers must do their best for clean air and environment along with the enhancement and sustainability of health.

\section{References}

1. Falco, G.J. "City resilience through data analytics: A human-centric approach", International Conference on Sustainable Design, Engineering and Construction (2015).

2. Arriscadoa, D., Murosb, J.J., Zabalac, M. and Dalmaua, J.M. "Influence of school health promotion on 
the life habits of schoolchildren", An Pediatr (Barc), 83(1), pp. 11-8 (July 2015).

3. Balakrishnan, K., Cohen, A. and Smith, K.R. "Addressing the burden of disease attributable to air pollution in India: The need to integrate across household and ambient air pollution exposures", Environmental Health Perspectives, 122(1), A6-A7 (2014).

4. Smith, K.R., Bruce, N., Balakrishnan, K., et al. "Millions dead: How do we know and what does it mean? Methods used in the comparative risk assessment of household air pollution", Annual Review of Public Health, 35(1), pp. 185-206 (2014).

\section{Biographies}

Pouran Raeissi received her $\mathrm{PhD}$ in the area of educational psychology and research from University of Kansas in 1989. She also received an MBA from Multimedia University, Malaysia, in 2012. She is currently an Associate Professor in the Department of Health Management and Medical Information in the Iran University of Medical Sciences.

Mohamad Taghi Ahmadian received his $\mathrm{PhD}$ in Mechanical Engineering from University of Kansas in 1986. He served as an Assistant Professor in University of Missouri from 1984 to 1985, and an Assistant Professor in University of Kansas from 1986 to 1987. He started working as an Assistant Professor in Sharif university of Technology as of 1989. At present, he is a Professor in the School of Mechanical Engineering in Sharif University of Technology, Tehran, Iran. 